\title{
Barbed Olympic Motto
}

\author{
Chenyu Wang \\ P.E. Department, Zhengzhou Institute of Aeronautical Industry Management \\ Zhengzhou 450015, Henan, China \\ E-mail: wchenyu@126.com
}

Received: January 6, $2011 \quad$ Accepted: January 20, 2011 doi:10.5539/ass.v7n6p194

\begin{abstract}
Although there are many positive meanings in the Olympic motto, its improper use and understanding will also lead to some negative effects. It makes sports that build our body become seeds that corrode the health of athletes. Excessive compliance with its value ethics will result in positive deviation of athletes, and a variety of tides to set up records in the society and may ignore the rights of survival of the weak. As a matter of fact, the Olympic motto itself is not a problem. The problem is that human being has not realized the other side of its duality. According to this, its application field is pointed out.
\end{abstract}

Keywords: Olympic motto, Value ethics, Deviation behavior

Since its birth, the Olympic motto of "swifter, higher and stronger" has stimulated a lot of athletes to continuously climb on the peak of competition. It encourages the public not to fear difficulties, to forge ahead and to finally tread it underfoot when faced up with predicament of life. When the Olympic Games sweeps across the globe, the Olympic motto of "swifter, higher and stronger" has not only been implanted in the blood of athletes, but also has exerted profound influences on the orientation of value of human society. In the contemporary world, the positive significance of Olympic motto to the human society is to stimulate human kind to continuously break through obstacles and lay siege to perfection. However, any thing has its dual character, and the same is true with Olympic motto. The Olympic motto is just a barbed rose, which not only brings beauty to human being, but will also hurt the fingers of those who pick flowers if human body can not use it in an appropriate way. Nowadays, the Olympic motto of "swifter, higher and stronger" not only makes sports that build our body become seeds that corrode the health of athlete, but also produces some negative effects on the value ethics of human kind.

\section{Olympic motto becomes the seeds that corrode the health of athletes}

The Olympic motto of "swifter, higher and stronger" requires athletes to continuously pursue development, lay siege to perfection or approach to perfection, attempt to set up world records and become the particular group of being the first. In order to achieve this target, athletes have to resolve the issue of relativity and absoluteness of sports performance.

The relativity of sports performance of athletes means that the sports performance of athletes have to be compared with the performance of other athletes. This horizontal comparison determines that the competition ranking of athletes is decided by two factors, namely, the sports performance of oneself and the sports performance of his opponent. The sports performance of an opponent is an uncertain factor for all athletes, and this kind of uncertainty causes athletes at all levels to encounter with the pressure to improve their performance. Therefore, in order to obtain a good sports performance, all athletes have to be dedicated to training so as to maintain and improve their sports performance. This will necessarily lead to "excessive investment" in sports training and competition by athletes at all levels. That is to say, athletes are stimulated to practice hard, and their painstaking investment largely surpasses "social marginal value" after the technical level of athletes is enhanced. Excessive investment of athletes in sports training and competition will necessarily lead to excessive training. And if a sports event itself has high demand on the physical condition, it is not difficult to conclude in terms of logics that the excessive training of athletes will result in wound and health problems. Thus, the problem of relativity of sports performance causes athletes at all levels to train excessively. "Excessive training" is a kind of "reverse investment" as for athletes, and may bring some negative effects on the body and mind of athletes. (Wang Chenyu, 2009) 
The problem of absoluteness of sports performance of athletes means that athletes have to attain the extreme value of their own sports performance. From the perspective of philosophy, limitation means that the "quality" of an object has "limit", and if this limit is surpassed, the object may go over to the opposite side. When the sports performance of athletes attains its limitation, its threat to the body has started. According to our living experience, if a machine often operates under a full load, namely, it runs under its limitation, then its service life expectancy must be shorter than when it is used in a normal way. Hence, in those sports events led by physical condition which require athletes to attain the sports limitation, the more the human body approaches the limit of speed, power and endurance, the more its danger to the human body. More than that, some athletes who take part in sports events led by physical condition may exercise by surpassing the limitation in order to improve their sports performance. That is, they overrun with help of medicine. In such case, more danger will be caused to the human body. We can prove that from the cases (see Table 1) of sudden death in athletes reported by the media in the recent two decades.

\section{Insert Table 1 Here}

From Table 1, it can be found that, most of these athletes with sudden death took part in sports events that have high demand on physical condition, while the author hasn't found any case reported about sudden death of athletes in those skill sport events that have lower demand on physical condition, such as shoot and archery. Although the incidents of sudden death also occur in other fields, the case of sudden death of young adults rarely happens as often as in sports competition. This also proves that, participation in competition of training led by physical condition under the condition of limitation might endanger the body and health of athletes. On August 20, 2008, "1+1 News" in CCTV made a program about wound of athletes. In the program, the question-master Dong Qian's question and the interview answer of the national track-and-field team vice head coach Kan Fulin furthermore proved this problem. Dong Qian asked the national track-and-field team vice head coach Kan Fulin such as question, "What is the situation of wounds among athletes in the national track-and-field team"? Kan Fulin answered, "As far as the track and field event is concerned, wound of athletes is relatively common." The specially invited observer Jiang Chunyan also believed, wound or disease was more or less inevitable for athletes involved in professional sports (China Central Television News 1+1, 2008).

From the above analytic demonstration, it can be found that the Olympic motto of "swifter, higher and stronger" may cause sports which are supposed to facilitate human health to become the gravedigger of the health of athletes. On one hand, the Olympic motto stimulates athletes to pull their socks up, forge ahead with determination and have the courage to set up new world records. On the other hand, pursuit of excellence is also revenging them in silence and makes them pursue excellence at the cost of health and even the heavy cost of their life. Therefore, if those sports events that have high demand on physical condition just focus on development and improvement, but without restraining, then it is quite possible that the Olympic motto might become a barbed rose and hurt athletes themselves. However, what is terrible is that, quite a large number of people fail to make a distinction between right and wrong and continue to let sports athletes who take part in physical condition leading sport events attempt for breaking through a world record. Even more, they wave their flag and shout their slogan for their athletes and let them slide further and further on the wrong track. These people find a beautiful outerwear for wound and disease of athletes. They define professional athletes as victims and contributors, since athletes arouse love of the public in sports at the cost of their wound and disease. In such way, athletes are able to participate in sports exercise with more enthusiasm and sports exercise becomes a sort of media for them to improve their life quality and health. Thus, it deserves that sacrifice of athletes brings such an effect. According to the author, sports which are supposed to build our body should not exclude those athletes who take part. If athletes are excluded, then the means of holding a sports competition is open for discussion. Then, this leads us to rethink about the significance of existence of such physical condition leading sport events that endanger human health. Whether it is necessary to evaluate excellence and victory of physical condition leading sport events with a new evaluation standard?

\section{The negative effects caused by its value ethics}

Generally speaking, ethics is philosophical refection on moral phenomena from the perspective of the concept and refers to a series of concepts about guiding behaviors. The value ethics of the Olympic motto refers to the value orientation guided by the Olympic motto. The value ethics of the Olympic motto mainly includes pursuit of having no limit and establishing world records. Although this kind of value orientation has great positive significance, it is just like a rose which is beautiful in appearance but has thorn. When athletes and the social public exercise this kind of value ethics, it is unavoidable that their excessive compliance with this value ethics may bring about some negative effects. 


\subsection{Positive deviation behavior of athletes caused}

The Olympic motto of "swifter, higher and stronger" stimulates athletes to pursue endlessly. In order to realize this value ethics, athletes would chase after their dreams without doubt. When they are dedicated to achieving success, any external constraint can be ignored by them. They are willing to make sacrifice and pay the price for the sports they are involved in. Besides, they also refuse to surrender in the presence of pain, pressure and fear. Excessive compliance with the value ethics of the Olympic motto causes quite a lot of athletes to take part in a competition even with a wound or disease. The Chinese volleyball player Zhao Ruirui took part in the Athens Olympic Games in 2004 under the circumstance that her fracture had not been recovered yet. The American athlete Batik Lazear completed the 500 motorcycle race in Indianapolis in 1996 even with ache of fracture in his back. His father said that he did not intend to lose this opportunity, let alone thinking about withdrawing from the competition. Although he was wounded, he still insisted on training for four hours each day. Until the sports competition season was over, he hadn't allow making a surgery on the fracture in his intervertebral disc that pressed his nerves. Athletes abide by the value ethics of the Olympic motto and take the risk of sacrificing their health to manifest their morality and health condition, which may result in high rate of wounds and diseases in particular sport events. What's more, when athletes comply too much with this kind of value ethics, a positive deviation behavior might be generated that is different from violence and taking any forbidden drug, which has been neglected by the society. The reason for this is that, sometimes, sports heroes reported by media currently are often those athletes who take the risk of their own safety and happiness to chase after the value ethics of the Olympic motto. Media commentators speak highly of those athletes who take part in a competition even with wound or disease on them and give highly positive comments to those athletes who have operations one by one in order to return to the competition terrain and take part in the competition. The media just add fuel to the fire, which only cause athletes to excessively abide by the value ethics of the Olympic motto. This sort of positive deviation behavior of athletes may do harm to both their mind and body. Thus, the media have to be prudent to propagandize and compliment this kind of value ethics and ought to publicize when athletes should comply with this value ethics.

\subsection{The current of setting up all sorts of records in the society caused}

The Olympic motto of "swifter, higher and stronger" requires athletes to set up records of competition performance, since establishment of an Olympic record will also be considered a marvelous achievement by the world. With wide and extensive popularization of the Olympic Games, currently this kind of value ethics to set up a world record has already been extended in meaning to all aspects in the social life and it seems that whatever kind of record is set up is always an extremely marvelous event. Often, human being pay the price of their life in order to create these strange records. For instance, during the "World Sauna Championship Contest" held in Finland in 2010, contestants were intended to set up the record of long duration of time in the sauna room under a high temperature. When the final had been held for 6 minutes, two contestants were shocked. One of these two contestants was from Russia who died and the Finland rival was also sent to the hospital with emergency Nevertheless, under the direct of the tide of creating Olympic record, people haven't witnessed the danger of excessive pursuit of the culture of setting up a record. A variety of record institutions in the society to set up and declare records have been established just like mushrooms after rain and it seems that all circles in the society also enjoy in such institutions. For the time being, the most well-known record declaration institution in the world in "Guinness World Records", and the most famous record declaration institution in China is an entertainment programme held by the nationally authoritative media called as "Do You Want to Challenge?" In this entertainment programme, the content of challenge frequently is simply boredom and vulgar. At present, China has also set up a non-government institution called "China World Records Association". Among all reasons for declaration of records publicized officially by the association, there are three issues which let people suspect the motive of setting up this institution: 1) visible value added, added value of you yourself or your project with unexpected effect; 2) focus of the media, which appeals eyes of the world and becomes the focus of the media; 3) uniqueness. The world record, the symbol of your uniqueness. One declaration of the record will benefit you all your lifetime. Thus, it can be seen, the purpose of declaring a record in the world is just to arouse focus of the media and aimed for economic profits. Researchers do not deny the positive significance of human kind establishing some world records. Nevertheless, if we place too much emphasis on the record establishment behavior of human body, that might also lead to egomania and autophilia of human being to their own competence and result in lots of irrational behaviors as well as some negative outcomes. Therefore, negative influences of this grotesque and gaudy desire for setting up a record with extremely strong utilitarian in the society have already exceeded the positive effects. Hence, we have to reflect, in a rational way, on the vulgar behavior of setting up a record which wastes both manpower and money. 


\subsection{Its life logic ignoring the survival right of the weak}

The Olympic motto of "swifter, higher and stronger" has to be realized through competition. Then, competition becomes the social life logic strengthened by the value ethics of the Olympic motto. Yet, achieving success through competition is the unique legal approach, which is also the fair approach to decide who deserves what in the society. If people believe in this, they should believe that those who possess authority and wealth should also gain what they have, since they have achieved success in the competition. This, invisibly, correspond with the way in which the ruling class looks at the world and makes sports become the tool to strengthen their privilege, status, orientation and value in the society. In fact, the social life ethics which emphasizes competition is a typical "law of the jungle". That is, the weak are the prey of the strong. Namely, the weak have no choice but to be little accounted of and suppressed for their ability is the lowest? If we come to comprehend the human society with this social life logic, it is quite likely that we will ignore the survival and rights of development of the weak in the society and might compel the weak to accept this irrational social situation or to struggle to resist. As a result, human tragedy incidents might be caused, which is not favorable for the entire harmony of human society.

\subsection{A mistake caused in language logic}

The Olympic value ethics of "sifter, higher and stronger" is currently often interpreted by the media as the limits of athletes to surpass themselves. "Beyond the limits" has already become the synonym of the value ethics of the Olympic motto. As a matter of fact, the value ethics of "beyond the limits" per se is an error in language logic. "Xin Hua Dictionary" defines limits as such, 1) the highest height and limit allowing for no addition at all; 2) if the variable $X$ changes according to a certain rule and reaches a constant $C$ without limits, then $C$ is called as the limit of X. Thus, it can be seen that, limit is the highest point of an object, and how comes that the highest point can be exceeded? Hence, in the world of language, there is no "beyond the limits" at all, and there is only "reaching the limits". However, in all sorts of sports books and media in China, the expression "beyond the limit" is often applied. This kind of language error generated by the value ethics of the Olympic motto should arouse our due attention.

\section{Conclusions}

Although the Olympic motto has lots of positive meanings, its inappropriate use by human kind may bring about some negative effects. Thus, the Olympic motto is just like a barbed rose, which although may bring beauty to human beings, it might also hurt the finger of those who pick its flowers without care. As a matter of fact, the Olympic motto itself has no right or wrong, and what is wrong is that human beings are unaware of the other side of its duality. With reflection for several years, researchers have summarized a rule about problems existing in cognition of human kind, that is, human beings have a common failing in their cognition that when they come to know a thing, they tend to put their concentration on its positive side and magnify its effects. This blinded desire for money often makes one apply a thing to all fields without distinguishing black from white. As a consequence, inappropriate use may lead to negative influences. Just like the Olympic motto, if we apply the value ethics of making perfection more perfect of "swifter, higher and stronger" to the material products created by human kind, then its significance is always positive and is helpful for human kind to economize the entire development cost and improve utilization effect of resources. However, if this motto is applied to the potential development of human body, our biased understanding of it might cause the sports that are supposed to facilitate the health of human being to become the gravedigger of the physical and psychological health of athletes just as athletes develop their competitive capacity without limit. Hence, this also brings us such an enlightenment, that is, we have to distinguish the pros and cons of anything and make clear the scope of its application. Or else, just as Lenin said, sometimes, even if the truth stepped on step forward, it might turn to be a fallacy.

\section{References}

[Online] Available: http://news.sina.com.cn/s/p/2010-08-09/105320856543.shtml.

[Online] Available: http://www.shijiejilu.org.cn/.

[Online] Available: http://www.sports.sina.com.cn/.

China Central Television News 1+1. (2008). Behind Wound and Disease of Athletes: Whether "Swifter, Higher and Stronger" Can Be with Health? August 20.

Editing Group of "Olympic Science". (1999). Olympic Science. Beijing: Higher Education Press, 54-55.

Research Center of the Commercial Press. (2001). Xin Hua Dictionary. Beijing: The Commercial Press, 54.

Wang, Chenyu. (2009). The Attendant Phenomena of China Athletic Sports Development and the Systematic Construction of Its Restraint Mechanism Theory. Doctor Thesis of Beijing Sport University, 49. 
Table 1. Typical cases of internationally well known athletes with a sudden death

\begin{tabular}{|c|c|c|c|c|}
\hline Athletes & Country & $\begin{array}{l}\text { Requirement of the } \\
\text { sport event on the } \\
\text { physical condition }\end{array}$ & $\begin{array}{l}\text { Time of } \\
\text { sudden } \\
\text { death }\end{array}$ & $\begin{array}{c}\text { Age of } \\
\text { sudden } \\
\text { death }\end{array}$ \\
\hline Bias & USA & Basketball/high & 1986 & 22 \\
\hline Dresser & Germany & Shot /high & 1987 & 26 \\
\hline Hamman & USA & Volleyball/high & 1988 & 31 \\
\hline Joyner (record holder) & USA & $100 \mathrm{~m} \& 200 \mathrm{~m} / \mathrm{high}$ & 1998 & 38 \\
\hline Julian Yearwood & USA & Football /high & 2003 & 33 \\
\hline Vivien.Foe & Cameroon & Football /high & 2003 & 28 \\
\hline Saranson & France & Vehicle/high & 2003 & 23 \\
\hline $\begin{array}{c}\text { Pantani (champion of Tour } \\
\text { de France) }\end{array}$ & Italy & Vehicle/high & 2004 & 34 \\
\hline Arielle Newman & USA & $\begin{array}{l}\text { Long-distance } \\
\text { running/high }\end{array}$ & 2007 & 17 \\
\hline Ryan Shay & USA & $\begin{array}{c}\text { Long-distance running } \\
\text { /high }\end{array}$ & 2007 & 28 \\
\hline $\begin{array}{c}\text { Ronikos (Champion for two } \\
\text { Olympic Games) }\end{array}$ & Hungary & canoeing /high & 2008 & 36 \\
\hline
\end{tabular}

